\title{
Hereditary breast cancer - what we have learned in the last decade
}

\author{
Renata Mendes de Freitas $1,2 *$ (), Pedro Medeiros ${ }^{3}$ (), \\ Maximiliano Ribeiro Guerra ${ }^{1}$ (), Maria Teresa Bustamante-Teixeira ${ }^{1}$ (b)
}

\section{ABSTRACT}

This literature review aims to inform and assist physicians and other health professionals in managing all information related to hereditary breast cancer, which is in constant and rapid growth, allowing for improvement in patient care and assistance. In addition, we seek to better identify which patients are eligible for the clinical criteria of association with risk of hereditary breast cancer, based on international recommendations and highlighting the main high and moderate penetrance genes that make up the multigenic panels for germline investigation in breast cancer, as well as the possibilities of clinical management that must be considered when complex decisions are required in clinical practice. Nowadays, there is more interest in population screening, in a greater supply of genetic tests, more genes included in multigene panels - allowing the search for genetic counseling - , apart from the need for clinical-decision support.

KEYWORDS: hereditary breast and ovarian cancer syndrome; screening; genetic counseling; genetic testing; treatments; risk reduction.

\section{LITERATURE REVIEW}

\section{Breast cancer and hereditary predisposition}

Breast cancer is the most common malignant neoplasm whose mortality rates are the highest among the females worldwide. In Brazil, 66,280 new cases were estimated per year for the triennium 2020-2022 (43.74 cases per 100,000 women) $)^{1,2}$. Although there are several risk factors, breast cancer is associated with environmental, reproductive, genetic and lifestyle factors; family history is considered an important etiological factor ${ }^{3}$.

The hereditary factor is a cause identified in $10-15 \%$ of breast cancer cases, and is associated with the Hereditary Breast and Ovarian Cancer Syndrome (HBOC), Li-Fraumeni Syndrome, Cowden syndrome, Peutz-Jeghers syndrome and hereditary diffuse gastric cancer in which lobular breast carcinoma may manifest in women ${ }^{4-6}$.

The hereditary predisposition is most commonly seen in individuals and families with some clinical features such as: diagnosis of breast cancer in patients $\leq 45$ years of age; breast cancer in men; personal and family history of ovarian, pancreas, bowel, endometrial, and prostate cancers at a younger age; and Ashkenazi Jewish origin?

\section{Pathogenic variants}

HBOC is mainly related to pathogenic variants in the $B R C A 1$ and $B R C A 2$ genes, which consist of germline mutations and account for almost $30 \%$ of all cases of hereditary breast cancer ${ }^{8,9}$. Other genes also have pathogenic variants associated with increased risk for hereditary breast cancer, such as TP53, CHEK2, ATM, STK11, PALB2, PTEN, among others, which demonstrates the complex genetic involvement when it comes to predisposition to this disease $\mathrm{e}^{10}$.

Over a lifetime, the presence of a pathogenic variant in $B R C A 1$ or $B R C A 2$ can increase the risk of breast cancer by up to $85 \%$. For ovarian cancer, estimates reach $46 \%$ when the $B R C A 1$ gene is involved and $20 \%$ when the $B R C A 2$ gene is involved ${ }^{4,11,12}$. The BRCA1 and BRCA2 genes, identified in the 1990s, are involved in the activation of DNA repair in response to cellular stress, playing crucial roles in chromatin remodeling, transcriptional control and cell cycle regulation, with tumor suppressor effects primarily attributed to cell cycle checkpoints and DNA repair ${ }^{13-15}$. Some mutations are more common in individuals from specific ethnic or geographic groups. This is due to the presence of initiating mutations which probably arose several generations ago in

1'Postgraduate Program in Public Health, Universidade Federal de Juiz de Fora - Juiz de Fora (MG), Brazil.

${ }^{2}$ Laboratory of Congenital Malformation Epidemiology, Fundação Oswaldo Cruz - Rio de Janeiro (RJ), Brazil.

${ }^{3}$ Medical School, Universidade Federal de Juiz de Fora - Juiz de Fora (MG), Brazil.

*Corresponding author: renatafreitas.mendes@gmail.com

Conflict of interests: nothing to declare.

Funding: Coordination for the Improvement of Higher Education Personnel (CAPES), and the National Post-Doctoral Program (PNDP) (process number 88882.316108/2019-01).

Received on: 08/03/2021. Accepted on: 11/23/2021. 
this population. In Ashkenazi Jews (descendants of Central and Eastern Europe), three specific initiating mutations were identified: 185delAG and 5382insC in the BRCA1 gene, and 6174delT in the $B R C A 2$ gene, and the same family group may have all three mutations. These variants are present in $2 \%$ of individuals in this group of women and are responsible for approximately $50 \%$ of early-onset breast cancer cases ${ }^{16}$.

Another founder mutation identified in Portuguese Caucasian families with cases of breast cancer is the insertion Aluc.156_157insALU in exon 3 of the $B R C A 2$ gene, which promotes DNA rearrangements, altering the nucleotide sequence. The Brazilian ethnic composition also makes room for founder mutations in our population ${ }^{17-19}$. Another tumor suppressor gene called TP53, associated with the Li-Fraumeni syndrome, leads to increased risk for multiple tumors, including osteosarcoma, bowel cancer, adrenocortical carcinoma, leukemia, lymphoma, and brain cancer in addition to breast can$\mathrm{cer}^{20}$. This syndrome has an interesting peculiarity in patients diagnosed in the South and Southeast regions of Brazil: the founder mutation p.R337H has a prevalence of $0.3 \%$ due to the founder effect related to the movement of drovers in Brazilian territory ${ }^{21}$. The PTEN gene, responsible for cell cycle control, is associated with the Cowden syndrome and usually causes malignant tumors in the thyroid, breast and endometrium. Women with this syndrome have $25 \%$ to $50 \%$ risk of developing breast cancer, while the risk of endometrial carcinoma can reach $10 \%{ }^{5}$.

Pathogenic variants involving the STK11 gene are associated with the Peutz-Jeghers syndrome, which increases the lifetime risk of breast cancer in women by up to $50 \%{ }^{5}$. Furthermore, genes involved in the pathways of DNA double-strand break (DSB) such as CHEK2, RAD51, BRIP1 and PALB2, may also be associated with hereditary cancer predisposition ${ }^{22}$.

Most cases of breast cancers are invasive and the prognosis depends on the stage of the disease at the time of diagnosis ${ }^{23}$. In general, in developing countries, diagnoses occur at advanced stages, which is mainly due to the deficiency in promoting early detection ${ }^{24}$. In non-menopausal women, breast cancer represents a biologically more aggressive disease, with frequent adverse histopathological features and worse prognosis when compared to women over 50 years of age ${ }^{25}$.

Hereditary breast cancer with $B R C A 1$ mutation often results in triple-negative breast cancers - approximately $80 \%$ of $B R C A 1$ mutation $\operatorname{cases}^{24,26,27}$. Histological characterization of tumors with BRCAl germline mutations suggests high histological grade, atypical medullary features, high proliferation rates, inflammatory infiltrates, and invasive borders. On the other hand, $B R C A 2$ mutation are related to tumors with a higher risk of contralateral breast cancer and estrogen receptor positivity in most cases $^{24,28}$.

\section{Screening for hereditary breast cancer}

Although physical examination is important to establish doctor-patient relationships and to evaluate symptomatic patients, it plays a less important role in breast cancer screening when compared to imaging methods such as mammography, magnetic resonance imaging (MRI) and ultrasonography, since it has low sensitivity in detect the disease and is thus insufficient to rule it out. In patients at increased risk, the sensitivity of the physical examination is even lower. However, it continues to be recommended once or twice a year for women aged 20-25 years of age and carrying pathogenic variants in BRCA1, BRCA2, TP53 or PTEN 29 .

For women in the breast cancer predisposition group, early mammographic screening is adopted, considering the earlier development of the disease, with the incorporation of complementary imaging tests such as MRI and ultrasound due to the limitations of the mammography examination for age groups below 40 years in the female population ${ }^{30-32}$.

In the general population, mammography has shown to be related to a reduction in mortality rates, although its usefulness is less understood in women with pathogenic variants in BRCA1, BRCA2, TP53, PTEN and STK11, or with history of chest irradiation in the age of 10 to 30 years. In this group, annual mammography is recommended starting from 30 years old, with adjuvant MRI ${ }^{10,29}$.

The guidelines related to the presence of pathogenic variants of moderate penetrance are less well-defined: annual mammography is recommended from the age of 40 onwards for patients with variants in $A T M, C H E K 2$ and $N B N$; and from the age of 30 onwards for cases of variants in PALB2, $\mathrm{CDH1}$ and $\mathrm{NFl}^{10,29}$.

Although mammography remains an appropriate tool to screen the general population, its use alone may be insufficient to detect patients at increased risk of developing breast cancer. The method has less sensitivity in denser breasts, commonly present in younger patients, who constitute one of the groups considered at increased risk for hereditary breast cancer ${ }^{29}$.

The MRI has a higher sensitivity compared to mammography to diagnose breast cancer in patients with hereditary predisposition. It is recommended annually from 25 to 30 years of age onwards in this group of women, also being considered annually from 30 to 50 years of age onwards - the age group in which mammography becomes the primary screening method ${ }^{29}$.

A comparative analysis using a simulation model of pathogenic variants in $B R C A 1$ and $B R C A 2$ demonstrated that annual MRI from 25 years old onwards, accompanied by alternating digital mammography from the age of 30 onwards, is probably the most effective screening strategy, being related to the highest life expectancy ${ }^{33}$.

According to data in the literature, when MRI and mammography were combined, the sensitivity goes up to $93 \%$. Women with previous breast cancer are at greater risk of developing secondary tumors in the treated and contralateral breast; therefore, the combined use of imaging tests is also recommended ${ }^{30}$. 
Guidelines for MRI screening in women with moderate penetrance pathogenic variants are also not so well defined. Annual MRI is considered for patients with variants in ATM, CHEK2 and $N B N$ from the age of 40 onwards, and the age of 30 onwards for patients presenting variants in $P A L B 2, C D H 1$ and $N F 1^{29}$.

Recommendations for discontinuing MRI screening in patients at increased risk vary between age groups over 50 years old - except for patients with dense breasts -, and after the age of 75 or when the life expectancy of the patient is set at less than 10 years ${ }^{10,29}$.

Ultrasonography, although not used as a routine method, can be useful as a complementary method in selected patients. Sensitivity is lower than that of MRI but comparable to that of mammography in young patients at increased risk. Therefore, in this group, it may be indicated mainly in women with dense breasts, pregnant women, lactating women or women who cannot undergo MRI ${ }^{29}$.

Although it does not provide many additional benefits in detecting cancer, the ultrasound can be used to increase the specificity of MRI by ruling out benign lesions. Furthermore, its adjuvant use may be more convenient and economical for shortterm follow-up and also in guided biopsies ${ }^{30}$.

Although breast cancer is more common among women, men who carry mutations in the BRCA2 gene may be at increased risk of developing the disease. In this case, annual clinical breast exam and monthly self-examination are recommended from the age of 35 onwards. Due to the low incidence of breast cancer in this group, even in those at increased risk, there are no studies to determine the value of additional screening methods ${ }^{29}$.

\section{Genetic counseling and molecular research}

Genetic counseling is a multifaceted process that can help to identify patients and family members who carry a mutation associated with increased risk of cancer. Genetic research should always be accompanied by pre- and post-test counseling, as to clarify all the possibilities of results, the limitations of the tests to be performed, and the possibilities of prevention, as well as to present the follow-up strategies and evaluate the chances of disease occurrence or recurrence in patients or relatives ${ }^{34}$.

International cancer research bodies propose guidelines that alert experts to pay attention to individuals at increased risk of hereditary cancers ${ }^{35}$.

According to guidelines by the National Comprehensive Cancer Network (NCCN), individuals who meet at least one of the following criteria should be referred for genetic counseling: personal history of breast and/or ovarian cancer; diagnosis under 50 years of age (in case of triple-negative breast cancer, personal history of two breast cancer diagnoses regardless of age of onset, and known mutation in a cancer-susceptibility gene within the family); several close family members with related cancers (breast, ovary, colon, endometrial, prostate, or pancreatic); diagnosis of breast cancer in men; and people of Ashkenazi Jewish ancestry with personal history of breast, ovarian and/or pancreatic cancer ${ }^{10}$.

In recent years, genetic testing has been allied to clinical practice. Until recently, the test was mainly performed by patients with a prominent family history of cancer encompassing a limited number of genes associated with a high or moderate risk of hereditary cancer. With the advent of the Next Generation Sequencing (NGS) molecular technique, panel genetic testing has become more widely used ${ }^{36}$.

Thus, there is scientific evidence of a clear association between hereditary cancer and some gene groups of high and moderate penetrance, with the presence of pathogenic variants that bring some possibilities of interference in therapeutics and disease management. In addition, the tracking of family members not yet affected by the disease is possible ${ }^{10}$.

The largest Brazilian study carried out by Palmero et al. sought to identify recurrent mutations in BRCA1 and BRCA2 that could be included in a low-cost genetic panel used as screening method for patients with predisposition to hereditary cancer. The study was carried out based on 649 genetic tests with pathogenic or probable pathogenic variants, obtained from 28 public and private health centers from 11 Brazilian states. In total, 126 mutations were identified in the BRCA1 gene and 103 in the BRCA2 gene, with 26 new variants identified in both genes ${ }^{19}$.

Table 1 lists some of the most prevalent mutations identified by the study.

However, some mutations were reported exclusively in certain geographic regions of the country, which suggests their founder effect and highlights the huge molecular heterogeneity and limited knowledge about these genes in the Brazilian population ${ }^{19}$.

Table 1. Mutations identified by Palmero et al. ${ }^{19}$ in at least three probands

\begin{tabular}{|c|c|c|c|}
\hline$B R C A 1$ & n (\%) & BRCA2 & n (\%) \\
\hline c.5266dupC & $\begin{array}{c}89 \\
(20.2)\end{array}$ & c.2808_2811delACAA & $\begin{array}{c}20 \\
(9.6)\end{array}$ \\
\hline c.3331_3334delCAAG & $\begin{array}{c}45 \\
(10.2)\end{array}$ & c.5946delT & $\begin{array}{c}15 \\
(7.2)\end{array}$ \\
\hline c.68_69delAG & $\begin{array}{c}19 \\
(4.3)\end{array}$ & c.156_157insAlu & $\begin{array}{c}11 \\
(5.3)\end{array}$ \\
\hline c. $211 \mathrm{~A}>\mathrm{G}$ & $\begin{array}{c}17 \\
(3.9)\end{array}$ & c.6405_6409delCTTAA & $\begin{array}{c}10 \\
(4.8)\end{array}$ \\
\hline c. $5074+2 T>C$ & $\begin{array}{c}14 \\
(3.2)\end{array}$ & $c .2 T>C$ & $\begin{array}{c}8 \\
(3.8)\end{array}$ \\
\hline c.470_471delCT & $\begin{array}{c}11 \\
(2.5)\end{array}$ & c.1138delA & $\begin{array}{c}7 \\
(3.4)\end{array}$ \\
\hline c. $1687 C>T$ & $\begin{array}{c}10 \\
(2.3)\end{array}$ & c. $9382 C>T$ & $\begin{array}{c}7 \\
(3.4)\end{array}$ \\
\hline c. $4675+1 G>A$ & $9(2.0)$ & c. $2266 C>T$ & $\begin{array}{c}3 \\
(1.4)\end{array}$ \\
\hline
\end{tabular}

Source: prepared by the authors based on data taken from the article by Palmero et al. ${ }^{19}$ 
To date, more than 35 candidate genes related to high and moderate risk of breast cancer have been suggested ${ }^{9,28}$. However, only few of these known genes had their variants significantly associated with breast cancer susceptibility, even in cases of positive family history or early diagnosis of the disease ${ }^{9,37}$.

By the same token, the use of multigene panels in genetic tests has considerably increased the number of patients diagnosed with a variant of uncertain significance (VUS), which reinforces the need for better models predictive of pathogenicity and increased efforts to help classify these variants, such as co-segregation analyses, personal and family history, co-occurrence of pathogenic variants, and histological and molecular characteristics of tumors ${ }^{9,38}$.

In order to better define the set of genes associated with breast cancer risk, Dorling et al. created a panel with 34 known genes that show an association with or susceptibility to breast cancer. The study included women with $(60,466)$ and without breast cancer $(53,461)$ from 25 countries who took part in population-based studies and studies based on families with a history of breast cancer, making up the Breast Cancer Association Consortium $(\mathrm{BCAC})^{36}$.

Variants that cause alteration in protein function were associated with a significant risk of breast cancer $(\mathrm{p}<0.0001)$ in 5 genes: $A T M$, BRCA1, BRCA2, CHEK2 and PALB2 (95\%CI2.10-10.57). Susceptibility to breast cancer was also observed in 7 genes: $B A R D 1$ (OR=2.09; 95\%CI 1.35-3.23), RAD51C (OR=1.93; 95\%CI 1.20-3, 11), RAD51D (OR=1.80; 95\%CI 1.11-2.93), PTEN(OR=2.25; 95\%CI 0.85-6.00), NF1 (OR=1.76; 95\%CI 0.96-3.21), TP53(OR=3.06; 95\%CI 0.63-14.91) and MSH6 (OR=1.96; 95\%CI 1.15-3.33) (Table 2) ${ }^{36}$.

Table 2. The 34 genes in the study by Dorling et al. ${ }^{36}$

\begin{tabular}{c|c}
\hline ABRAXAS1 & MSH2 \\
\hline AKT1 & MSH6 \\
\hline ATM & MUTYH \\
\hline BABAM2 & NBN \\
\hline BARD1 & NF1 \\
\hline BRCA1 & PALB2 \\
\hline BRCA2 & PIK3CA \\
\hline BRIP1 & PMS2 \\
\hline CDH1 & PTEN \\
\hline CHEK2 & RAD50 \\
\hline EPCAM & RAD51C \\
\hline FANCC & RAD51D \\
\hline FANCM & RECQL \\
\hline GEN1 & RINT1 \\
\hline MEN1 & STK11 \\
\hline MLH1 & TP53 \\
\hline MRE11 & XRCC2 \\
\hline
\end{tabular}

Source: prepared by the authors based on data taken from the article by Dorling et al..$^{19}$
Following similar objectives, the North American study conducted by Hu et al. involving 12 population-based studies used a panel with 28 breast cancer-predisposing genes evaluated in 32,247 case-patients and 32,544 control-patients (Table 3) 37-39.

Pathogenic variants were identified in 12 genes established as predisposing to breast cancer in $5.03 \%$ of cases and $1.63 \%$ of controls. Corroborating the study by Dorling et al., the BRCAI (OR=7.62; 95\%CI 5.33-11.27) and BRCA2 (OR=5.23; 95\%CI 4.096.77) genes are linked to a high risk for breast cancer; and the PALB2 (OR=3.83; 95\%CI 2.68-5.63) and CHEK2 (OR=2.47; 95\%CI 2.02-3.05) genes, to moderate risk ${ }^{36}$.

In women affected by the disease, the most prevalent mutations were observed in BRCA1 (OR=7.62; 95\%CI 5.33-11.27), BRCA2 (OR=5.23; 95\%CI 4.09-6.77) and PALB2 (OR=3.83; 95\%CI 2.685.63). In unaffected women, most mutations were observed in CHEK2 and ATM, indicating a moderate risk for breast cancer ${ }^{39}$.

In summary, both studies showed a significant association between breast cancer risk and variants of 8 genes - BRCA1, BRCA2, PALB2, BARD1, RAD51C, ATM and CHEK2. However, most genes tested were not significantly associated with breast cancer, and the larger the multigene panel, the higher the VUS rates ${ }^{36,39}$.

Women who carry mutations in CHEK2 and ATM have tumors that express estrogen receptors, which may benefit from antiestrogen therapies such as tamoxifen, raloxifene or aromatase inhibitors. However, studies involving chemoprevention have not been carried out in women with mutations in CHEK2 or ATM; and even among carriers of mutations in $B R C A 1$ and $B R C A 2$, the absorption of tamoxifen is low $w^{40}$.

With regard to other types of cancer, carriers of CHEK2 mutations are considered to be at high risk for colon cancer, and carriers of ATM mutations are considered at risk for pancreatic

Table 3. The 28 genes in the study by Hu et al. ${ }^{39}$

\begin{tabular}{c|c}
\hline ATM & MRE11A \\
\hline BARD1 & MSH2 \\
\hline$B L M$ & MSH6 \\
\hline$B R C A 1$ & NBN \\
\hline BRCA2 & NF1 \\
\hline BRIP1 & PALB2 \\
\hline CDH1 & PTEN \\
\hline CDKN2A & RAD50 \\
\hline CHEK2 & RAD51C \\
\hline ERCC3 & RAD51D \\
\hline FANCC & RECQL \\
\hline FANCM & RINT1 \\
\hline MLH1 & SLX4 \\
\hline XRCC2 & TP53
\end{tabular}

Source: prepared by the authors based on data taken from the article by Hu et al. ${ }^{39}$ 
cancer. However, colon cancer screening is recommended for carriers of CHEK2 mutations, but not for ATM mutation carriers when it comes to pancreatic cancer in ${ }^{10}$.

It is important to emphasize that the use of genetic panels and analyses of genomic rearrangements are great allies in the investigation of hereditarily-predisposed cancer, and that panels with multiple investigated genes must be well evaluated, as they can generate data for which clinical management has not yet been determined and, therefore, some patients may choose to have a genetic test with a smaller panel of genes, containing only high and moderate risk genes, as these provide the best-characterized cancer risk estimates and management recommendations ${ }^{41}$.

Table 4 presents nine genes associated with breast cancer risk, including estimated lifetime risk, other malignancies associated with the presence of gene mutations, and individualized management and screening approaches according to NCCN guidelines ${ }^{10}$, as well as data presented in studies by Dorling et al. ${ }^{36}$, Bharucha et al. ${ }^{42}$, Owens et al. ${ }^{35}$ and Shiovitz et al. ${ }^{28}$.
Genes known to be associated with high and moderate risk of breast cancer are frequently mentioned in the scientific literature ${ }^{6,43,44}$ while likely candidate genes for hereditary breast cancer susceptibility are investigated. The study by Torrezan et al. analyzed 23 of these genes in 42 women evaluated for increased risk of hereditary breast cancer from a South American hospital cohort, with no identified variants in the BRCA1, BRCA2, TP53 and $C H E K 2$ genes (c.1100delC). However, possible deleterious variants were identified in 12 new candidate genes associated with hereditary cancer, also evaluated in previous studies: $N O T C H 2$, DNAH7, RAF1, MST1R, LAMB4, NIN, SLX4, ERCC1, SLC22A16, PTPRD, ARHGEF12 and ERBB29.

These findings provide a set of new genes that can be reanalyzed, bringing new evidence of a possible breast carcinoma phenotype, including case-control studies in different populations, especially in cases where there is strong evidence for hereditary predisposition and no variant that justify the clinical phenotype ${ }^{9,45}$.

Table 4. Pathogenic mutations in high- and moderate-risk genes associated with breast cancer

\begin{tabular}{|c|c|c|c|}
\hline Germline mutation & $\begin{array}{l}\text { Cumulative risk* of } \\
\text { breast cancer }\end{array}$ & $\begin{array}{l}\text { Other associated } \\
\text { malignancies }\end{array}$ & Screening guidelines ${ }^{\dagger}$ \\
\hline$B R C A 1$ & $85 \%$ & $\begin{array}{l}\text { Ovary, fallopian tubes, } \\
\text { peritoneum, pancreas, } \\
\text { prostate, colon. }\end{array}$ & $\begin{array}{c}\text { 25-29 years }{ }^{\ddagger} \text { : Annual MRI (mammography if MRI is not } \\
\text { available); } 30-75 \text { years: annual mammography and MRI; } \\
\text { discuss preventive mastectomy and bilateral salpingo- } \\
\text { oophorectomy after pregnancy. }\end{array}$ \\
\hline$B R C A 2$ & $65 \%$ & $\begin{array}{l}\text { Ovary, fallopian tubes, } \\
\text { peritoneum, pancreas, } \\
\text { prostate, melanoma. }\end{array}$ & $\begin{array}{l}\text { 25-29 yearsł: Annual MRI (mammography if MRI is not } \\
\text { available); } 30-75 \text { years: annual mammography and MRI; } \\
\text { discuss preventive mastectomy and bilateral salpingo- } \\
\text { oophorectomy after pregnancy. }\end{array}$ \\
\hline TP53 & $85 \%$ & $\begin{array}{l}\text { Sarcomas and CNS, } \\
\text { adrenocortical, } \\
\text { gastrointestinal, } \\
\text { and associated with } \\
\text { radiation. }\end{array}$ & $\begin{array}{l}\text { 25-29 years: Annual MRI (mammography if MRI is not } \\
\text { available); } 30-75 \text { years: annual mammography and MRI; } \\
\text { discuss bilateral preventive mastectomy. }\end{array}$ \\
\hline PTEN & $67-87 \%$ & $\begin{array}{l}\text { Thyroid, endometrium, } \\
\text { colorectal, renal. }\end{array}$ & $\begin{array}{c}\text { 30-35 years": Annual MRI and mammography; discuss } \\
\text { preventive mastectomy. }\end{array}$ \\
\hline $\mathrm{CDH} 1$ & $42-60 \%$ & Diffuse gastric cancer. & $\begin{array}{l}30 \text { years or older: annual mammography, consider annual } \\
\text { MRl; insufficient evidence for preventive mastectomy }\end{array}$ \\
\hline STK115 & $44-50 \%$ & $\begin{array}{l}\text { Colorectal, stomach, } \\
\text { small intestine, } \\
\text { pancreas, ovary, Sertoli } \\
\text { cell tumor. }\end{array}$ & $\begin{array}{l}\text { 25-29 yearsł: Annual MRI; } 30 \text { years and older: annual } \\
\text { mammography and MRI. }\end{array}$ \\
\hline ATM & $20 \%$ & Pancreas. & $\begin{array}{l}\geq 40 \text { years: annual mammography; consider annual MRI; } \\
\text { insufficient evidence for preventive mastectomy, or } \\
\text { prescription of radiation therapy. }\end{array}$ \\
\hline CHEK2 & $20-25 \%$ & $\begin{array}{l}\text { Colorectal, stomach, } \\
\text { prostate, kidney and } \\
\text { thyroid. }\end{array}$ & $\begin{array}{l}\geq 40 \text { years: annual mammography; consider annual MRI; } \\
\text { insufficient evidence for preventive mastectomy. }\end{array}$ \\
\hline PALB2 & $33 \%-59 \%$ & Pancreas. & $\begin{array}{l}\geq 30 \text { years: annual mammography and MRI; insufficient } \\
\text { evidence for preventive mastectomy. }\end{array}$ \\
\hline
\end{tabular}

MRI: magnetic resonance imaging; CNS: central nervous system. *Estimated cumulative risk up to 70 years of age; †Due to a lack of local studies, the recommendations in Brazil are based on international data; ${ }^{\ddagger}$ Or 10 years before the youngest person affected in the family; ${ }^{5} \mathrm{Gene}$ evaluated in the study by Dorling et al. ${ }^{36}$, but without statistical significance of risk.

Source: Prepared by the authors, based on information taken and adapted from ${ }^{10,28,35,36,42}$. 


\section{Therapeutic and risk-reducing approaches in hereditary breast cancer}

The term "risk reduction" has been considered more appropriate than "prophylactic" in recent times, as no mastectomy can remove all of the breast tissue. Studies have shown a reduction in breast cancer risk of approximately $95 \%$ in $B R C A 1$ and $B R C A 2$ mutation carriers undergoing bilateral risk-reducing mastectomy (BRRM) in combination with oophorectomy, and a reduction in risk of approximately $90 \%$ in those with intact ovaries ${ }^{46-48}$.

A recent systematic review confirms the benefit of BRRM in reducing breast cancer incidence and mortality in patients at high risk for breast cancer predisposition such as carriers of $B R C A 1$ and $B R C A 2$ mutations, but this evidence requires rigorous prospective studies due to methodological flaws in the existing literature ${ }^{49}$. Contralateral mastectomy as risk reduction (CMRR) data for patients who had unilateral breast cancer are not conclusive, as existing studies show a reduction in the incidence of contralateral breast cancer but no definitive survival benefit ${ }^{50-53}$.

The main treatment strategies for breast cancer are surgery and systemic treatment. One of the main concerns in the surgical treatment of breast cancer with a pathogenic variant for $B R C A 1$ and $B R C A 2$ is whether the outcome of treatment with breastconserving surgery (BCS) combined with adjuvant radiotherapy is equivalent to radical mastectomy ${ }^{54}$.

A study compared results of the surgical method (BCS combined with radiotherapy versus mastectomy) in cases of breast cancer with pathogenic variants $B R C A 1$ and $B R C A 2$. According to the work by Onitilo et al., a higher 10-year survival was observed in the group undergoing BCS with adjuvant radiotherapy (BCS: $80.9 \%$ versus mastectomy: $67.2 \%$ ), in addition to lower rates of local recurrence ${ }^{54}$.

However, it is known that women who carry mutations in $B R C A 1$ and BRCA2 are more likely to develop a secondary cancer, that is, ipsilateral or in the contralateral breast. For these patients, a bilateral mastectomy is recommended, as studies suggest that women who carry mutations in BRCA1 and BRCA2 and who undergo bilateral mastectomy are less likely to die of breast cancer than women who have been treated with unilateral mastectomy ${ }^{46-52}$.

A meta-analysis encompassing 526 patients with a pathogenic variant in BRCA1 and BRCA2 and 2,320 patients with sporadic breast cancer showed no difference in overall survival rates between these groups. However, patients with mutations in $B R C A 1$ and $B R C A 2$ had a greater recurrence of ipsilateral breast cancer than patients with sporadic breast cancer, with a mean follow-up of more than six years ( $R R=1.51$; 95\%CI 1.15-1.98) $)^{55}$.

Radiation after $\mathrm{BCS}$ is not performed only in very exceptional cases. Given the essential role of the $B R C A 1$ and $B R C A 2$ genes in DNA repair of other cancer-inducing genes in humans, questions have been raised regarding the possible complications of radiotherapy in breast cancer involving pathogenic variants in
$B R C A 1$ and $B R C A 2^{15}$. However, a study by Pierce et al. showed no significant difference in radiation complication rates between women carrying $B R C A 1$ and $B R C A 2$ mutations versus women with sporadic cancer ${ }^{56}$.

In this setting, radiotherapy also plays an important role after mastectomy. Indications should be similar in both radical surgery and conservative mastectomy. Traditionally, radiotherapy is indicated for patients with four or more affected lymph nodes, positive surgical margins, or with tumors larger than 5 $\mathrm{cm}$. However, there is a debate about the role of radiotherapy in patients with 1-3 metastatic lymph nodes and the role of secondary factors such as age, molecular subtype and angiolymphatic invasion in the decision-making about the use of radiotherapy after mastectomy, remaining quite controversial ${ }^{48}$.

In patients with the Li-Fraumeni syndrome presenting with germline mutations in the TP53 gene, exposure to radiotherapy increases the risk of a second cancer. In these patients there is an inactivation of DNA repair mechanisms and activation of apoptosis, so the susceptibility to radio-induced tumors can accelerate the appearance of a second neoplasm ${ }^{57}$.

The repair pathway by homologous recombination of damaged DNA - in which there is loss of function caused by mutations present in the $B R C A 1$ and $B R C A 2$ genes - lead to very similar phenotypes, which fall within the hereditary predisposition to breast and ovarian cancer. Likewise, mutations in $R A D 51 C$, $B R I P 1, P A L B 2$ and others can lead to a phenotype similar to that of $\mathrm{HBOC}^{58}$.

By taking into account the chemotherapy-based treatment, which causes DNA damage requiring repair genes of the homologous recombination pathway to induce a repair response, the status of the pathogenic variant in $B R C A 1$ and $B R C A 2$ is considered a decisive factor to predict sensitivity to chemotherapy ${ }^{15}$.

The profile of genomic structural alterations caused specifically by homologous recombination deficiency (HRD) repair has been studied as potential markers of pathway deficiency through scores, which may be useful in evaluating the association not only with the response rate to chemotherapy, but also with clinicopathological and overall survival factors ${ }^{59}$.

In in vitro studies, cells with the $B R C A 1$ variant were shown to be more sensitive to platinum-based chemotherapeutic agents, as they disrupt the DNA structure. They also showed greater resistance to microtubule-inhibiting chemotherapies such as taxanes. These findings were supported by data from patients with BRCA1 and BRCA2 pathogenic variant breast cancer who underwent palliative or neoadjuvant taxane-only chemother$a_{p y}{ }^{50}$. However, there is insufficient evidence to exclude taxanes from adjuvant chemotherapy strategies in patients with breast cancer carrying mutations in $B R C A 1$ and $B R C A 2^{15}$.

Patients diagnosed with breast cancer at younger ages and carriers of mutations in high and moderate penetrance genes should have an individualized surgical treatment. Carriers of 
$B R C A 1$ and $B R C A 2$ mutations, for example, face more aggressive surgical interventions for therapeutic purposes and to reduce the risk of developing primary or contralateral breast cancer, which is increased ${ }^{57}$.

However, breast-conserving surgery, as well as skin-sparing mastectomies with or without preservation of the nippleareolar complex, have been shown safe and to provide a better restoration. Selecting the best surgical approach for this group of patients requires taking into account several factors, including genetic risk, personal and family history, and the patient's own preferences ${ }^{57}$.

\section{AUTHORS' CONTRIBUTIONS}

R.M.F: conceptualization, investigation, formal analysis, writing - original. P.M.: investigation, formal analysis, writing original. M.R.G.: writing - review \& editing. M.T.B.T: writing review \& editing.

\section{REFERENCES}

1. Instituto Nacional de Câncer José Alencar Gomes da Silva. Estimativa 2020: incidência de câncer no Brasil. Rio de Janeiro: INCA; 2019.

2. Global Cancer Observatory. International Agency for Research on Cancer. Available from: https://gco.iarc.fr/.

3. de Paula LB, Santos RS, Lima PS, de Paula NM, Reis AAS. Os genes BRCA1 e BRCA2 e suas relações genéticas na predisposição aos carcinomas mamários hereditários e esporádicos. Revista EVS-Revista de Ciências Ambientais e Saúde. 2010;37(6). http://doi.org/10.18224/est.v37i6.1898

4. Prolla CMD, Silva PS, Netto CBO, Goldim JR, Ashton-Prolla P. Conocimiento del cáncer de mama y cáncer de mama hereditário em el personal de enfermería de un hospital público. Rev Latino-Am Enfermagem. 2015;23(1):90-7. https:// doi.org/10.1590/0104-1169.0185.2529

5. Ferraz VEF, Cury NM. Como o ginecologista pode orientar mulheres com antecedentes familiares de câncer? Rev Bras Ginecol Obstet. 2014;36(8):335-9. https://doi.org/10.1590/ SO100-720320140005104

6. Corso G, Montagna G, Figueiredo J, La Vecchia C, Romario UF, Fernandes MS, et al. Hereditary gastric and breast câncer syndromes related to CDH1 germline mutation: a multidisciplinary clinical review. Cancers (Basel). 2020;12(6):1598. https://doi.org/10.3390/cancers12061598

7. Berliner JL, Fay AM, Cummings SA, Burnett B, Tillmanns T. NSGC practice guideline: risk assessment and genetic counseling for hereditary breast and ovarian cancer. J Genet Couns. 2013;22(2):155-63. https://doi.org/10.1007/s10897-0129547-1

8. Silva FC, Lisboa BC, Figueiredo MC, Torrezan GT, Santos EM, Krepischi AC, et al. Hereditary breast and ovarian cancer: assessment of point mutations and copy number variations in Brazilian patients. BMC Med Genet. 2014;15:55. https://doi. org/10.1186/1471-2350-15-55

9. Torrezan GT, de Almeida FGSR, Figueiredo MCP, Barros BDF, de Paula CAA, Valieris R, et al. Complex landscape of germline variants in Brazilian patients with hereditary and early onset breast cancer. Front Genet. 2018;9:161. https://doi.org/10.3389/ fgene.2018.00161
10. National Comprehensive Cancer Network. NCCN Clinical Practice Guidelines in Oncology. Genetic/familial high-risk assessment: breast and ovarian. NCCN Guidelines Version 3.2019; January 18, 2019. Available from: https://www2.trikobe.org/nccn/guideline/gynecological/english/genetic_ familial.pdf.

11. Palmero EI, Alemar B, Schüler-Faccini L, Hainaut P, Moreira-Filho CA, Ewald IP, et al. Screening for germline BRCA1, BRCA2, TP53 and CHEK2 mutations in families at-risk for hereditary breast cancer identified in a population-based study from Southern Brazil. Genet Mol Biol. 2016;39(2):210-22. https://doi.org/10.1590/1678-4685GMB-2014-0363

12. Antoniou A, Pharoah PDP, Narod S, Risch HA, Eyfjord JE, Hopper JL, et al. Average risks of breast and ovarian cancer associated with BRCA1 or BRCA2 mutations detected in case series unselected for family history: a combined analysis of 22 studies. Am J Hum Genet. 2003;72(5):1117-30. https://doi. org/10.1086/375033

13. Miki Y, Swensen J, Shattuck-Eidens D, Futreal PA, Harshman K, Tavtigian S, et al. A strong candidate for the breast and ovarian cancer susceptibility gene BRCA1. Science. 1994;266(5182):6671. https://doi.org/10.1126/science. 7545954

14. Wooster R, Neuhausen SL, Mangion J, Quirk Y, Ford D, Collins $\mathrm{N}$, et al. Localization of a breast cancer susceptibility gene, BRCA2, to chromosome 13q12-13. Science. 1994;265(5181):208890. https://doi.org/10.1126/science.8091231

15. Lee A, Moon BI, Kim TH. BRCA1/BRCA2 pathogenic variant breast cancer: treatment and prevention strategies. Ann Lab Med. 2020;40(2):114-21. https://doi.org/10.3343/ alm.2020.40.2.114

16. Ashton-Prolla P, Vargas FR. Prevalence and impact of founder mutations in hereditary breast cancer in Latin America. Genet Mol Biol. 2014;37(1 suppl 1):234-40. https://doi.org/10.1590/ S1415-47572014000200009

17. Teugels E, Brakeleer S, Goelen G, Lissens W, Sermijn E, Grève J. De novo Alu element insertions targeted to a sequence common to the BRCA1 and BRCA2 genes. Hum Mutat. 2005;26(3):284. https://doi.org/10.1002/humu.9366 
18. Peixoto A, Santos C, Rocha P, Pinheiro M, Príncipe S, Pereira D, et al. The c.156_157insAlu BRCA2 rearrangement accounts for more than one-fourth of deleterious BRCA mutations in northern/central Portugal. Breast Cancer Res Treat. 2009;114(1):31-8. https://doi.org/10.1007/s10549-0089978-4

19. Palmero EI, Carraro DM, Alemar B, Moreira MAM, Ribeiro-Dos-Santos Â, Abe-Sandes K, et al. The germline mutational landscape of BRCA1 and BRCA2 in Brazil. Sci Rep. 2018;8(1):9188. https://doi.org/10.1038/s41598-01827315-2

20. Li FP, Fraumeni Jr JF. Soft-tissue sarcomas, breast cancer, and other neoplasms: a familial syndrome? Ann Intern Med. 1969;71(4):747-52. https://doi.org/10.7326/0003-4819-71-4-747

21. Garritano S, Gemignani F, Palmero EI, Olivier M, MartelPlanche G, Le Clavez-Kelm F, et al. Detailed haplotype analysis at the TP53 locus in p.R337H mutation carriers in the population of Southern Brazil: evidence for a founder effect. Hum Mutat. 2010;31(2):143-50. https://doi.org/10.1002/ humu.21151

22. Toss A, Tomasello C, Razzaboni E, Contu G, Grandi G, Cagnacci A, et al. Hereditary ovarian cancer: not only BRCA 1 and 2 genes. Biomed Res Int. 2015;2015:341723. https://doi. org/10.1155/2015/341723

23. Reis-Filho J, Pusztai L. Gene expression profiling in breast cancer: classification, prognostication, and prediction. Lancet. 2011;378(9805):1812-23. https://doi.org/10.1016/S01406736(11)61539-0

24. Godet I, Gilkes DM. BRCA1 and BRCA2 mutations and treatment strategies for breast cancer. Integr Cancer Sci Ther. 2017;4(1). https://doi.org/10.15761\%2FICST.1000228

25. Coelho AS, Santos MAS, Caetano RI, Piovesan CF, Fiuza L, Machado RLD, et al. Predisposição hereditária ao câncer de mama e sua relação com os genes BRCA1 e BRCA2: revisão da literatura. RBAC. 2018;50(1):17-21. https://doi. org/10.21877/2448-3877.201800615

26. Turner NC, Reis-Filho JS. Basal-like breast cancer and the BRCA1 phenotype. Oncogene. 2006;25(43):5846-53. https:// doi.org/10.1038/sj.onc.1209876

27. Bayraktar S, Glück S. Systemic therapy options in BRCA mutation-associated breast cancer. Breast Cancer Res Treat. 2012;135(2):355-66. https://doi.org/10.1007/s10549-012-2158-6

28. Shiovitz S, Korde LA. Genetics of breast cancer: a topic in evolution. Ann Oncol. 2015;26(7):1291-9. https:/doi. org/10.1093\%2Fannonc\%2Fmdv022

29. Lee TC, Reyna C, Shaughnessy E, Lewis JD. Screening of populations at high risk for breast cancer. J Surg Oncol. 2019;120(5):820-30. https://doi.org/10.1002/jso.25611

30. Urban LABD, Chala LF, Bauab SP, Schaefer MB, Santos RP, Maranhão NMA, et al. Recomendações do Colégio Brasileiro de Radiologia e Diagnóstico por Imagem, da Sociedade Brasileira de Mastologia e da Federação Brasileira das Associações de Ginecologia e Obstetrícia para o rastreamento do câncer de mama. Radiol Bras. 2017;50(4):244-9. http://doi. org/10.1590/0100-3984.2017-0069

31. Thuler LC. Considerações sobre a prevenção do câncer de mama feminino. Rev Bras Cancerol. 2003;49(4):227-38. https:// doi.org/10.32635/2176-9745.RBC.2003v49n4.2076
32. Pinto E, Campos R, Pinelo S, Gouveia A, Gonçalves J. Breast and gynecologic hereditary cancer. Acta Obstet Ginecol Port. 2012;6(1):20-32.

33. Lowry KP, Lee JM, Kong CY, McMahon PM, Gilmore ME, Chubiz JEC, et al. Annual screening strategies in BRCAl and BRCA2 gene mutation carriers: a comparative effectiveness analysis. Cancer. 2012;118(8):2021-30. https://doi.org/10.1002/ cncr.26424

34. Resta R, Biesecker BB, Bennett RL, Blum S, Hahn SE, Strecker MN, et al. A new definition of genetic counseling: national society of genetic counselors' task force report. J Genet Couns. 2006;15(2):77-83. https://doi.org/10.1007/ s10897-005-9014-3

35. Owens DK, Davidson KW, Krist AH, Barry MJ, Cabana M, Caughey AB, et al. Risk assessment, genetic counseling, and genetic testing for BRCA-related cancer: US preventive services task force recommendation statement. JAMA. 2019;322(7):65265. https://doi.org/10.1001/jama.2019.10987

36. Dorling L, Carvalho S, Allen J, González-Neira A, Luccarini $\mathrm{C}$, Wahlström $\mathrm{C}$, et al. Breast cancer risk genes association analysis in more than 113,000 women. N Engl J Med. 2021;384(5):428-39. https://doi.org/10.1056/ NEJMoa1913948

37. Easton DF, Pharoah PDP, Antoniou AC, Tischkowitz M, Tavtigian SV, Nathanson KL, et al. Gene-panel sequencing and the prediction of breast-cancer risk. N Engl J Med. 2015;372(23):2243-57. https://doi.org/10.1056/NEJMsr1501341

38. Freitas R, Guerra M, Fayer V, Campos A, Cintra J, Warren, J, et al. Histological and immunohistochemistry characteristics for risk of hereditary breast cancer in a cohort of Brazilian women. No prelo. 2021.

39. Hu C, Hart SN, Gnanaolivu R, Huang H, Lee KY, Na J, et al. A population-based study of genes previously implicated in breast cancer. N Engl J Med. 2021;384(5):440-51. https://doi. org/10.1056/NEJMoa2005936

40. Narod SA. Which genes for hereditary breast cancer? N Engl J Med. 2021;384(5):471-3. https://doi.org/10.1056/ NEJMe2035083

41. Peshkin BN, Isaacs C. Genetic testing and management of individuals at risk of hereditary breast and ovarian cancer syndromes. UpToDate. 2021. Available from: https://www. uptodate.com/contents/genetic-testing-and-management-ofindividuals-at-risk-of-hereditary-breast-and-ovarian-cancersyndromes.

42. Bharucha PP, Chiu KE, François FM, Scott JL, Khorjekar GR, Tirada NP. Genetic testing and screening recommendations for patients with hereditary breast cancer. Radiographics. 2020;40(4):913-36. https://doi.org/10.1148/rg.2020190181

43. Schon K, Tischkowitz M. Clinical implications of germline mutations in breast cancer: TP53. Breast Cancer Res Treat. 2018;167(2):417-23. https://doi.org/10.1007/s10549-017-4531-y

44. Evans MK, Longo DL. PALB2 mutations and breast-cancer risk. N Engl J Med. 2014;371(6):566-8. https://doi.org/10.1056/ NEJMe1405784

45. Nielsen FC, van Overeem Hansen T, Sørensen CS. Hereditary breast and ovarian cancer: new genes in confined pathways. Nat Rev Cancer. 2016;16(9):599-612. https://doi.org/10.1038/ nrc. 2016.72 
46. Rebbeck TR, Friebel T, Lynch HT, Neuhausen SL, van't Veer L, Garber JE, et al. Bilateral prophylactic mastectomy reduces breast cancer risk in BRCA1 and BRCA2 mutation carriers: the PROSE study group. J Clin Oncol. 2004;22(6):1055-62. https:// doi.org/10.1200/JCO.2004.04.188.

47. Hartmann LC, Lindor NM. The role of risk-reducing surgery in hereditary breast and ovarian cancer. N Engl J Med. 2016;374(5):454-68. https://doi.org/10.1056/NEJMra1503523

48. Meijers-Heijboer H, van Geel B, van Putten WL, HenzenLogmans SC, Seynaeve C, Menke-Pluymers MB, et al. Breast cancer after prophylactic bilateral mastectomy in women with a BRCA1 or BRCA2 mutation. N Engl J Med. 2001;345(3):159-64. https://doi.org/10.1056/NEJM200107193450301

49. Carbine NE, Lostumbo L, Wallace J, Ko H. Risk-reducing mastectomy for the prevention of primary breast cancer. Cochrane Database Syst Rev. 2018;4(4):CD002748. https://doi. org/10.1002/14651858.CD002748.pub4

50. Evans DGR, Ingham SL, Baildam A, Ross GL, Lalloo F, Buchan I, et al. Contralateral mastectomy improves survival in women with BRCA1/2-associated breast cancer. Breast Cancer Res Treat. 2013;140(1):135-42. https://doi.org/10.1007/s10549-013-2583-1

51. Heemskerk-Gerritsen BAM, Rookus MA, Aalfs CM, Ausems MGEM, Collée JM, Jansen L, et al. Improved overall survival after contralateral risk-reducing mastectomy in BRCAl/2 mutation carriers with a history of unilateral breast cancer: a prospective analysis. Int J Cancer. 2015;136(3):668-77. https:// doi.org/10.1002/ijc.29032

52. Metcalfe K, Gershman S, Ghadirian P, Lynch HT, Snyder C, Tung N, et al. Contralateral mastectomy and survival after breast cancer in carriers of BRCA1 and BRCA 2 mutations: retrospective analysis. BMJ. 2014;348:g226. https://doi. org/10.1136/bmj.g226
53. van Sprundel TC, Schmidt MK, Rookus MA, Brohet R, van Asperen CJ, Rutgers EJT, et al. Risk reduction of contralateral breast cancer and survival after contralateral prophylactic mastectomy in BRCA1 or BRCA2 mutation carriers. Br J Cancer. 2005;93(3):287-92. https://doi.org/10.1038/sj.bjc.6602703

54. Onitilo AA, Engel JM, Stankowski RV, Doi SAR. Survival comparisons for breast conserving surgery and mastectomy revisited: community experience and the role of radiation therapy. Clin Med Res. 2015;13(2):65-73. https://doi. org/10.3121/cmr.2014.1245

55. Valachis A, Nearchou AD, Lind P. Surgical management of breast cancer in BRCA-mutation carriers: a systematic review and meta-analysis. Breast Cancer Res Treat. 2014;144(3):44355. https://doi.org/10.1007/s10549-014-2890-1

56. Pierce LJ, Strawderman M, Narod SA, Oliviotto I, Eisen A, Dawson L, et al. Effect of radiotherapy after breast-conserving treatment in women with breast cancer and germline BRCA1/2 mutations. J Clin Oncol. 2000;18(19):3360-9. https:// doi.org/10.1200/JCO.2000.18.19.3360

57. Pouptsis A, Swafe L, Patwardhan M, Stavraka C. Surgical and systemic treatment of hereditary breast cancer: a mini-review with a focus on BRCA1 and BRCA2 mutations. Front Oncol. 2020;10:553080. https://doi.org/10.3389/fonc.2020.553080

58. Nakonechny QB, Gilks CB. Ovarian cancer in hereditary cancer susceptibility syndromes. Surg Pathol Clin. 2016;9(2):189-99. https://doi.org/10.1016/j.path.2016.01.003

59. Kim SJ, Sota Y, Naoi Y, Honma K, Kagara N, Miyake T, et al. Determining homologous recombination deficiency scores with whole exome sequencing and their association with responses to neoadjuvant chemotherapy in breast cancer. Transl Oncol. 2021;14(2):100986. https://doi.org/10.1016/j. tranon.2020.100986 